\title{
eGrids, a Catalyst for Improved Learning?
}

\author{
Matthew Dean \\ De Montfort University, United Kingdom
}

\begin{abstract}
Electronic marking grids (eGrids) are a mechanism for formative, summative and continuous assessment. These eGrids used in conjunction with viva based "driving tests" provide a mechanism for improving feedback to students and making the most of staff time spent in assessment. The eGrid is made available to students in read only format via the internet. Students may view their own grid to see progress so far and model the grades required to achieve their desired outcomes. Tutors have readwrite access to the grids and may input grades with guidance for improvement. The driving test style of assessment allows students to be critiqued on their work whilst allowing opportunity for them to recover any problems or misunderstandings. The study will adopt an action research approach to explore the impact and attitudes to the use of eGrids on two second year Computing modules. The paper takes into account quantitative and qualitative data from both staff and students along with a review of relevant pedagogic theory.
\end{abstract}

\section{Introduction}

One approach to assessment and feedback used for example by Universities such as Oxford and Cambridge involved students completing essays set by their tutor and then undertaking a formative assessment via viva and oral feedback. This style of assessment proved to be effective, however due to the many and increasing pressures faced by teaching staff the quality, quantity and timeliness of feedback has been undermined. [13]

Nicole and Mac Farlane [21] identify good feedback as "anything that might strengthen the students' capacity to self-regulate their own performance." This paper outlines the first year of an ongoing project aimed at improving feedback for students whilst making the most of the time staff spend in assessment. It is hoped that this mechanism will make some contribution to students' experience of improved feedback whilst being mindful of the demands on teaching staff.

The two second year modules used to pilot this approach are Multimedia and Internet Technology [11] and Internet Software Development [10]. Both modules are assessed by coursework only and make extensive use of on-line streamed video for a large amount of the taught material. All material for teaching, learning and assessment for the entire year is placed on-line to facilitate students' independent learning. In both cases the majority of the taught material is delivered during two hour lab sessions and one hour lectures. Both modules have been designed incorporating elements of Problem Based Learning (PBL). [22]

Multimedia and Internet Technology has been running for five years consisting of four assessment points. Each assessment point involved students making self and peer assessments the grades being verified by the tutor. The module typically has approximately 80 students resulting in around 320 units of assessment processed by one member of staff. This module has been adapted this year to make use of the eGrid model. The four assessment points have been retained along with much of the self / peer assessment. This year there is also an additional member of staff on the module assessing thirty percent of the cohort.

Internet Software Development is a new module specifically designed with the new assessment strategy in mind. It consists of three assessment points with one hundred students, resulting in three hundred assessment points distributed over three members of staff at a ratio of 2:2:1. The module incorporates aspects of team based learning based around SCRUM development.

The assessments for both modules revolve around the eGrid as a tool for dialogue incorporating the driving test to set the rules for that dialogue.

The eGrid is a spreadsheet which lists the marking criteria for all of the assignments on the module and is available to students in read only format via the internet from the start of the module. On the grounds of confidentiality it was considered an important feature of the system that students should not have access to each other's grids. Students may download their eGrid at any time to see their grade, review any feedback from their tutor and also model grades they need to obtain in the future. The eGrid is split into credit categories. Weightings may be applied to individual criteria and entire credit categories. 


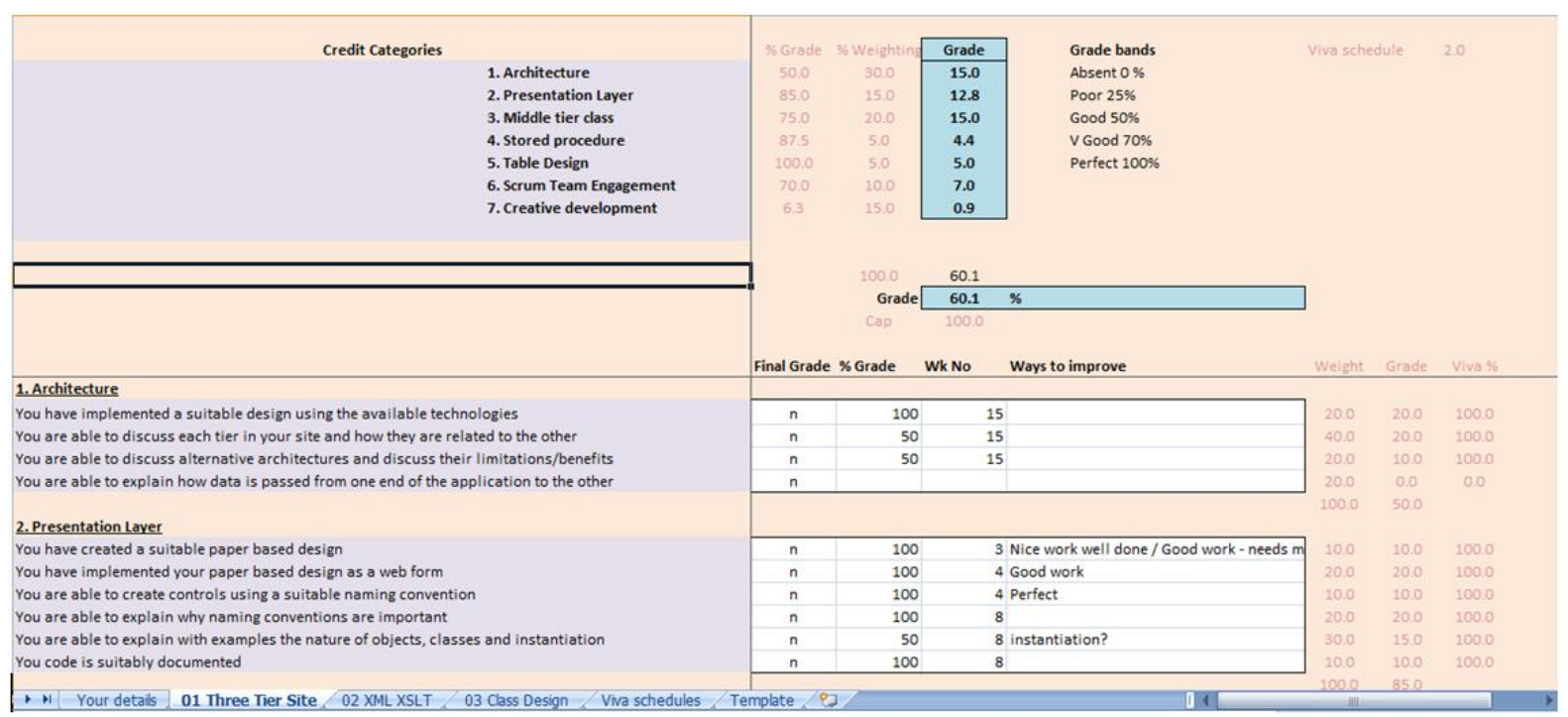

Figure 1. The eGrid

The current design of the eGrid allows grades to be time sensitive. For example a grade for a specific assessment criteria obtained in week 1 may obtain $100 \%$ of the available marks, the same grade obtained in week 20 may only attract $30 \%$ of the available marks. The decision was also taken to only allow specific percentage grades, 0,25,50,70 and $100 \%$. The intention was to remove any debate over small percentage values.

Members of staff have read-write access to each eGrid and may update a student's grid with any marks awarded, the week it was awarded and comments on how the student may improve their work / knowledge.

The driving test is a viva based assessment similar to a "Mini-Viva". [5]. The driving test allows students to re-take an assessment multiple times until they pass the work. The emphasis of the driving test is on assessment for learning.

Certain constraints may be applied in order to manage the volume of work and also to encourage students to manage their time. Driving tests may only be carried out during class to prevent students attempting to monopolise staff time. The assessment grade may be time sensitive to discourage students from delaying the assessment until the last moment. A system of "time outs" may be applied such that after a certain number of failed attempts during a class the student must wait until the following week to re take the assessment. Students may also be limited to attempting the test to once in a week.

Should a student show gaps in their knowledge they must rely on their peers and the teaching materials to fill these gaps. The tutor should resist the urge to prompt the student and the assessment mechanism works best if the tutor gives as little direct help as possible. It is important that students are given sufficient opportunity to problem-solve and thus construct their understanding of the subject matter.

Over the course of the module students are expected to make claims for credit. A claim for credit may be made against a single credit category. Claims for credit may be formative, summative or continuous. The model of assessment hopes to make use of feed forward modes of dialogue in addition to more traditional feedback.

The formative phase of the assessment starts at week one of the module and involves the students obtaining a self and peer assessment of work completed so far. Once they have obtained this peer assessment they may approach their tutor to claim for credits. Students may only claim for a single credit category per week at this point. At this stage of the process students may claim for credits on work that is incomplete. For example if a student is aware that a specific item of work is only worth $25 \%$ then they may obtain this grade along with feedback on how to improve.

Each assignment has a set deadline. After this deadline the work may not be modified. Shortly after the assignment is submitted review weeks are built into the schedule devoted entirely to assessment. During a review week the students work together in teams to apply a self and peer assessment. Having obtained this assessment they may claim credits from their tutor. During these review weeks students may claim for multiple credit categories on the grid. Feedback may be obtained on work completed so far however there is no longer opportunity at this stage to correct any omissions / errors.

Within the eGrid certain criteria are practical in nature, for example how well has a certain aspect been completed? Other criteria focus on the 
student's grasp of a particular topic. For example how well does the student understand a certain aspect of the theory? These criteria focussing on the student's knowledge offer scope for ongoing dialogue after the assignment deadline. In this case the time sensitivity of the eGrid may be used as in incentive to encourage students to learn aspects of the taught material.

\section{Literature Review}

In the new regime of funding in Higher Education National Student Survey Results are becoming more important to Universities. One consistent theme of NSS results is that feedback and assessment could be improved in H.E with scores of less than 55\%. [16], [17], [18], [19], [20]. NSS results however are not the only factors driving the need for improved assessment. High quality feedback is an essential driving force in student learning. [4]

There are a number of barriers to good feedback not least of which are pressures on staff time [13]. Beaumont et al [1] identify a number of points related to a potential fault line in student experience of feedback between College and University. This fault line serves to undermine the effectiveness of feedback in H.E. Their work focuses on the contrasting experiences of students who transfer from College to first year study at University. Many points arise from this study for example shifts in emphasis from formative to summative assessment, and learning moving from being tutor centred to resource centred. At the core of their work they propose a dialogue feedback model which includes preparatory guidance, in task guidance and performance feedback. This is conceptualised as a cyclical process which takes place during the assessment process.

Several factors are identified as promoting good feedback. Nicol, D. \& Macfarlane-Dick, D., [21] identify seven principles for good feedback. Good feedback should mutually identify standards and goals for both student and tutor. It should encourage reflection and self assessment on the part of the learner. Good feedback should provide high quality information to the learner. Students should be encouraged to develop positive beliefs and self esteem along with opportunities to close the gap between what is not known and what is to be learnt. Good feedback should also inform the content of the teaching. As well as creating dialogue good feedback must be immediate and timely. [7]

Beaumont et al recognise that tutors in H.E. devote a great deal of time to providing feedback to students. However this feedback may not be beneficial if it is seen by learners as too late to be applied to the assessment. In H.E. detailed assessment criteria are not always available for learners and there is less emphasis on draft copies and formative assessment. There may also be issues related to the student's ability to understand the feedback. In order for feedback to be of use to the learner it must be understandable to the receiver. [15], [24].

Staff may have legitimate concerns about spoon feeding students in providing an environment that reflects learning in college and school. There may be factors that could help to address these issues. Framing assessment as a community of practice may be one way of addressing these issues involving peer and self evaluation combined with real world examples and problems. [2] Students also should be given opportunities to construct new knowledge based on what they already know. [3]

\section{Research Rationale}

An action research approach has been taken with this work. Action research lends itself well to trialling pedagogic innovations. [9]

Although there is still a large amount of data still to be processed the following approaches have been taken to evaluate research findings so far.

One benchmark by which institutions are measured is the National Student Survey. In the light of this it was decided that NSS questions would be used as the basis of a questionnaire with the main aim of finding if the use of eGrids might make any positive impact on future NSS results.

Students completed the questionnaire which was split into two sections. Firstly the questionnaire asked students to rate assessment and feedback for this new approach only. Secondly the students were asked to complete the NSS questions for the other modules on the year reflecting on the assessment mechanisms used there. It is hoped that from these results some indication will be obtained as to the kind of impact the eGrids may have on NSS results.

The questions drawn from the NSS are:

- The criteria used in marking have been clear in advance;

- Assessment arrangements and marking have been fair;

- Feedback on my work has been prompt;

- I have received detailed comments on my work;

- Feedback on my work has helped me clarify things I did not understand.

A second source of qualitative data is drawn from the access $\operatorname{logs}$ and completion patterns for the eGrids. This data is only partially compiled for this paper as there is still a great deal of data to process. Data $\operatorname{logs}$ of access to the grids will ultimately be analysed to see when students access the grids along with frequency of access. Other data embedded in 
the logs relate to the week in which students obtained a grade therefore giving some indication of engagement in the feed forward process.

Qualitative data has been obtained via two focus groups, one for staff and the other for students. Both focus groups have been small at this stage, two students and four staff.

Finally results from the above sources will be considered in the light of research from other sources to verify the findings.

\section{Analysis of Findings}

Staff and students felt that the system was easy to understand from the start of the teaching. In general they found the on-line software reliable, secure and easy to access. Students felt that the continuous mode of assessment helps with time management. Staff new to teaching initially found the process confusing but ultimately found it very easy and useful.

Staff and students agree that the majority of students are very positive about the approach and have enjoyed the experience. Some comments indicate that this is an exciting approach, fairer than other assessment mechanisms. Tutors noted that it was possible to "see learning taking pace" due to the formative nature of the assessment. Staff commented that marking is quickly processed saving a lot of time as assessment is contained within the taught sessions. The process can, however, be an exhausting experience especially with a demanding group of students.

Perhaps the strongest point to be raised from the focus groups is the central role of dialogue in this mechanism of assessment. Dialogue surrounding the eGrid appeared to go some way to addressing different conceptions held by student and tutor as to what constitutes "success" [15]. The cycle of feedback and dialogue is very much at the heart of the eGrid model. [1]

Students and staff felt that dialogue at a one to one level helps to tailor the assessment to the needs of the student. Every student is different and with this model it was felt that there is a greater chance of tailoring teaching and assessment to individual needs. Tutors felt that this also gives opportunity to provide specific support as required.

One point raised by both tutors and students related to the role of technical terminology in staff student dialogue. There were some concerns on the part of students that technical terminology in general makes feedback opaque. This reflects the findings of Beaumont et al. Students were quite clear that this may be the fault of the student for not learning the material and also the fault of the tutor for not making themselves clear. There was, however, a strong feeling that feedback must be meaningful to the learner "meeting them where they are". Feedback was described as "the support mechanism by which we learn". It was felt that the strong dialogue present in this model allows for clarification of concepts and terminology between student and tutor. Tutors did note that students tended to shy away from the theoretical questions. They may be able to perform a certain task but find it difficult to explain the underlying concepts and processes. There were some notes of frustration on the part of the teaching staff that students sometimes took some time to get to grips with technical concepts and terminology. The above issues may reflect the finding that tutors see their feedback as more valuable than students do [6] along with the possible mismatch of requirements between tutor and learner related to the requirements of assessment [14]

The students did remark that there is a risk of a tutor becoming bogged down with specific students in this model. Some students may get neglected if they are not seen by the tutor. The students felt that the tutor needs to be organised, disciplined and fair with time spent with each student. Students also have the capacity to become angry if they feel that the process is not being handled fairly.

Another perceived outcome of the dialogue was that to some extent the assessment became self moderating. For example awarding a grade to one student made staff more conscientious and consistent knowing that the student will almost certainly be discussing their grade with a fellow student sitting next to them. Tutors did express a concern that the experience may become repetitive should a room full of students all find themselves stuck on the same problem.

Students also pointed out that eGrids promote an environment more like real world development, for example Rapid Application Development / Agile Development. The feeling was that vocational subjects such as programming should be assessed in a vocational manner. This seems to reflect the PBL apprenticeship elements of the module design. [22]

In this model feedback is instant. Students know what they did and what needs to be done to improve. The students felt that formative assessment allows for learning and corrective action when things are wrong. This mirrors many of the principles of good practice identified by Chickering \& Gamson [7] for example that good feedback is prompt feedback.

Students and staff felt that the electronic nature of the grid is an important aspect of the process. Students may view their current grades and model future grades without relying on the tutor for this information. The eGrids provided a higher level of detail than, for example, grade centre in Blackboard. They felt that the detailed grades on the eGrid to be valuable. Staff also appreciated the fact that the eGrid makes the grade calculations for you, especially with a sliding scale of marks. 
Table 1. Percentage NSS results for other modules on the same year

(A = Definitely Agree, B = Mostly Agree, $C=$ Neither Agree or Disagree, $D=$ Disagree, E = Definitely Disagree)

\begin{tabular}{|c|c|c|c|c|c|}
\hline & A & $\mathrm{B}$ & $\mathrm{C}$ & $\mathrm{D}$ & $\mathrm{E}$ \\
\hline The criteria used in marking have been clear in advance & 34 & 48 & 16 & 1.6 & 0 \\
\hline Assessment arrangements and marking have been fair & 31 & 52 & 11 & 4.9 & 0 \\
\hline Feedback on my work has been prompt & 23 & 41 & 28 & 6.6 & 1.6 \\
\hline I have received detailed comments on my work & 23 & 30 & 36 & 6.6 & 4.9 \\
\hline Feedback on my work has helped me clarify things I did not understand & 23 & 38 & 25 & 6.6 & 8.2 \\
\hline
\end{tabular}

Compare this with the results for the eGrids mode of assessment:

Table 2. Percentage NSS results for modules using eGrids

\begin{tabular}{|c|c|c|c|c|c|}
\hline & A & B & $\mathrm{C}$ & $\mathrm{D}$ & $\mathrm{E}$ \\
\hline The criteria used in marking have been clear in advance & 57 & 33 & 9.8 & 3.3 & 0 \\
\hline Assessment arrangements and marking have been fair & 52 & 31 & 16 & 3.3 & 0 \\
\hline Feedback on my work has been prompt & 51 & 38 & 6.6 & 8.2 & 0 \\
\hline I have received detailed comments on my work & 34 & 41 & 23 & 1.6 & 3.3 \\
\hline Feedback on my work has helped me clarify things I did not understand & 43 & 34 & 18 & 6.6 & 0 \\
\hline
\end{tabular}

These results appear to suggest that there is potentially a positive impact on NSS results based on the use of eGrids. It is also interesting to note the changes to the different sets of data:

Table 3. Changes in value for each criterion

\begin{tabular}{|c|c|c|c|c|c|}
\hline & A & $\mathrm{B}$ & $\mathrm{C}$ & $\mathrm{D}$ & $E$ \\
\hline The criteria used in marking have been clear in advance & 23 & -15 & -7 & 1.6 & 0 \\
\hline Assessment arrangements and marking have been fair & 21 & -21 & 4.9 & -2 & 0 \\
\hline Feedback on my work has been prompt & 28 & -3 & -21 & 1.6 & -2 \\
\hline I have received detailed comments on my work & 11 & 11 & -13 & -5 & -2 \\
\hline Feedback on my work has helped me clarify things I did not understand & 20 & -3 & -7 & 0 & -8 \\
\hline
\end{tabular}

In preparing for the review sessions it became necessary to create a printed version of the eGrids. The paper based version offered the flexibility for rough notes and annotations. Both tutors and students agreed that the paper based and electronic versions of the eGrids complimented each other. One important aspect is that together they provide a cross check of the record of grades. Staff may also give written feedback for students to reflect on to improve their knowledge.

There was also discussion about the nature of the feedback provided during the assessment. Students felt that concise verbal feedback was good; however, more detailed feedback needs to be written in note form. There are opportunities for feedback on both the paper version and electronic version of the eGrid.
It was also felt that students have different preferences so it was best to address both verbal and written feedback.

Discussion also related to how feedback may also be an uncomfortable experience for both student and tutor. Some students may feel threatened by feedback seeing it as criticism. The students were clear that they don't want positive feedback only, negative feedback has a place. It was accepted that less confident people may find viva intimidating and any student trying to pass off another person's work as their own would find the process uncomfortable. The students did feel, however, that if you have done the work and you know what you are talking about this should not be an intimidating process. 
Tutors also expressed some concerns about making negative comments being an inhibiting factor due to face to face nature of feedback. Staff expressed some concerns about upsetting or discouraging students if the feedback was too negative. Both staff and students did accept that there is a place for negative feedback. The students did also concede that some students will never make the most of feedback no matter what the mechanism. Good feedback should where possible have a positive impact on students' self esteem. [21]

One important aspect of the eGrids is the option to engage in feed forward assessment. Assessment that provides feedback is essential, however assessment that feeds forward offers opportunity for students to close the gap between their knowledge and the goal [8] Staff and students agreed that the enthusiasm for the feed forward aspect started well but tailed off to some extent as the modules progressed.

The students agreed that the feed forward assessment helped performance, however for some students it became less of a priority once they felt more confident with the work.

Both staff and students agreed that other pressures also undermined this process. Assignments on other modules, insufficient space between assessments and too much irrelevant content in a module added to poor student time management all serve to erode the feed forward aspect of the assessment. The students and staff also pointed out that not all students want one hundred percent being much more strategic about the grades they aspire to. Staff and students agreed that it is important to build sufficient time into the teaching for students to digest and reflect on the taught content.

To consider the results for the NSS questionnaire we shall take a three step process. Firstly we will look at the results for assessment and feedback for approaches used on other modules, secondly we will look at the results for this module only and lastly we will examine the change between the two sets of results. These percentage results are based on 61 students over the two modules taught by three different members of staff.

The results for assessment and feedback on other modules in the same year (excluding modules using the eGrids) are as follows:

- The cells marked in red indicate the peak percentage values for the results.

- Cells marked in green indicate the next value below the peak.

The results suggest that there is an improvement on the more positive feedback and a reduction in the negative. From the start of January 2012 usage patterns were logged on the server G677. These results indicate that from $1^{\text {st }}$ Jan $2012-6^{\text {th }}$ April 2012 there were 1646 individual access to eGrids on the system. Of the 154 students registered on the two modules 146 of them used the eGrids during this period (95\%). This amounts to an average of 11 accesses over a 13 week period for each student. This level of activity equates roughly to one access per week per students. This would appear to suggest that students are mostly accessing the eGrids during the taught sessions. However, if we look at access data based on numbers of students accesses per day we see the following patterns of usage (see Figure 2).

For each week we see that there is a peak of activity on Tuesday and Thursday when the taught sessions are run. There is however a fairly regular spike of activity on Monday and Wednesday which strongly suggest that the grids are being used for out of class work. This is also re-enforced by looking at the $\log$ of IP address activity. Of the 1646 access during the three month period $69 \%$ came from a University IP address and $31 \%$ came from an off campus address.

There is still a great deal of data to process in order to fully understand access patterns and possible impact on NSS results.

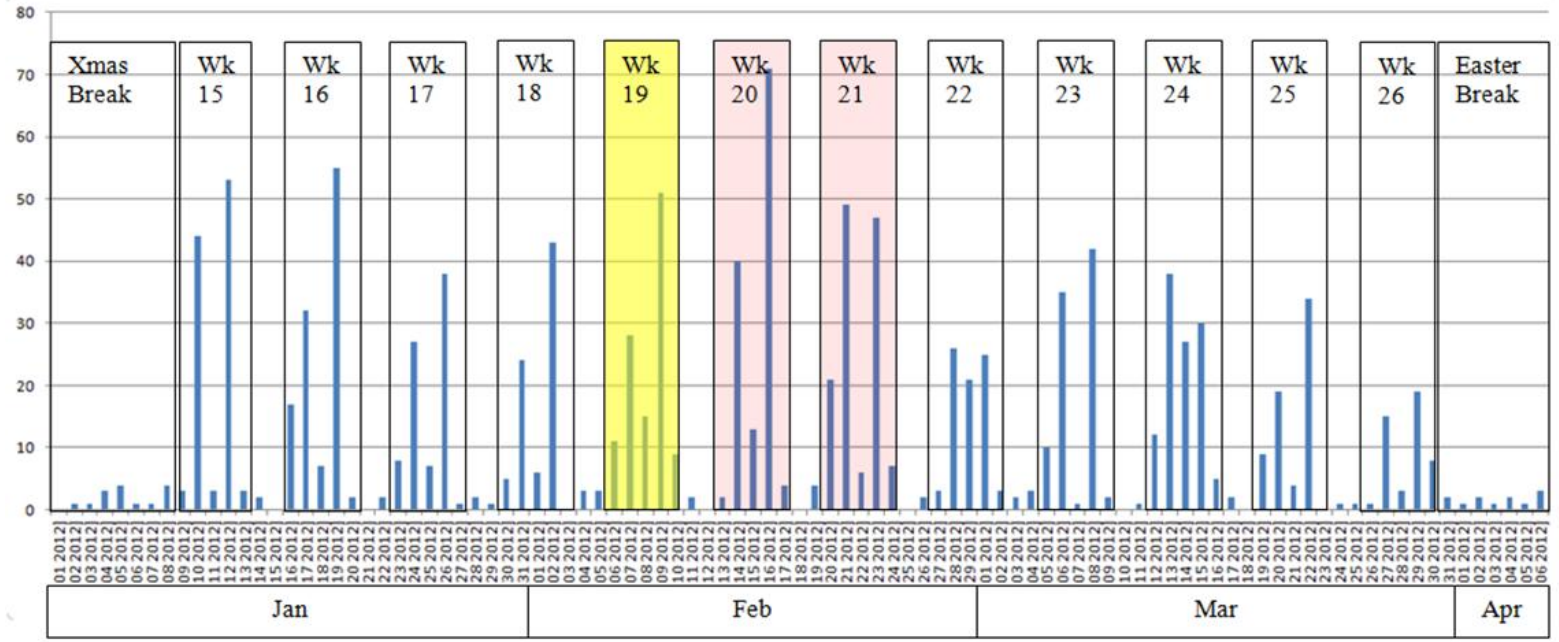

Figure 2. eGrid access record 


\begin{tabular}{|l|l|}
\hline \multicolumn{2}{|l|}{ Presentation Layer } \\
\hline $\begin{array}{l}\text { The web form validates the data entered and provides meaningful error } \\
\text { messages to the user. The controls on the web form are set up using a suitable } \\
\text { naming convention. Your presentation layer code is well documented. The } \\
\text { presentation layer code makes use of middle layer objects in such a way that it } \\
\text { has no idea of the database structure. }\end{array}$ \\
\hline Validation and clarity of error messages & \\
\hline Selection and configuration of controls & \\
\hline Standard of documentation & \\
\hline Correct design and use of middle layer classes & \\
\hline
\end{tabular}

Figure 3. Credit Category Detail

\subsection{The New Year}

The break prior to the start of this new teaching year has provided a valuable opportunity to reflect on the first run of the project and hopefully make improvements.

One issue that arose during the first year of the work related to managing the time spent in dialogue between tutor and student. The time spent with students had two issues that needed addressing. One part relates to the issue of fairness. If the tutor is spending too much time with one student to the neglect of others this creates a problem in the group. In one instance during the year this resulted in a dispute between one student and a member of staff. At the time this was addressed by raising the number of credit categories that could be claimed during a week from one to two, however fairness needed to be addressed in a much more structured manner. The second issue related to the time spent in dialogue placing excessive demands on teaching staff. Walking into a room full of students all wanting to make claims for credit could be quite a daunting experience.

An attempt to address the issue of fairness within the system has been made by strengthening the role of team based learning. On one module using the eGrids a form of SCRUM development had been applied with the students working in teams of four. The initial expectation was that students would simply provide evidence of engagement with the work outside of class. An impression of the team's cohesion was also formed as evidence by engagement in class. In the first year this was quite a light touch approach to team learning. During the new term a more structured approach is being taken.
Students are organised into teams at the start of the year and as before must provide evidence of team meetings outside of class. In this new session however students may only make claims for credits as part of a team. Each team has a schedule of meetings where they meet their tutor and each team member makes individual claims during that meeting. The individual claims may be constrained either by time, number of credit categories or both. So far a quarter of the way into the new teaching year this appears to have created a more structured, fairer and manageable approach to claiming for credits.

Strengthening the team based aspect of the approach has also helped to strengthen certain aspects of the pedagogy. It is interesting to note that many aspects of Team Based Learning fit well with the eGrids approach.

Four requirements for successful team based learning are that teams must be well formed and well managed, students must be accountable not only for their own work but also that of the team, students must receive frequent and timely feedback and the assessment must promote learning and the development of the team. [25]

The team based aspect of the approach also fits well with the collaborative elements of Problem Based Learning. Students working together in SCRUM teams have the opportunity to mirror real world practice that they will almost certainly encounter in industry. [22] 


\subsection{The Log Book}

A second feature of the new run of the process is the introduction of a paper based log book. [26] The log book has grown from the paper based eGrid which became a necessity as the first year developed.

The $\log$ book contains full details of the assignment specification, detailed clarification of the requirements of the marking scheme and a schedule where students may note the dates of their team's meetings.

The log book is now a central document in the dialogue with the students during a claim for credit. During a claim students and staff use the marking grid as the central focus of the dialogue. Students are expected to perform a self assessment and the tutor has the opportunity to annotate the book with relevant feedback.

One issue with the first run of the system was that it wasn't always clear as to the specific meaning of the marking criteria. In order to remove any potential ambiguity a new section was added to the grid containing a detailed description of the credit category. The addition of the log book also provides a formal document with annotations that may be fed into internal moderation processes.

\section{Comparison of Module Results}

A simple comparison of progression rates between modules is not necessarily the best measure of the success or failure of a specific module. There are many issues that serve to complicate the picture such as the difficulty of a specific subject (e.g. programming) and a huge range of other confounds that serve to cloud the relationship between a specific teaching learning strategy and overall student grades. It is also important to be sensitive to the use of such data should it run the risk of placing other modules in an unjustly negative light. This being the case the other modules will be made anonymous.

The first results are the pass rates for the four modules on the first of the two programmes. In this case the number of enrolled students is the same across all four modules. The eGrids module has a higher pass rate and average module mark.

Table 4. Achievement Statistics for 2011 - 2012

Cohort

\begin{tabular}{|l|l|l|l|}
\hline & Enrolled & $\begin{array}{l}\text { Pass } \\
\text { Rate }\end{array}$ & $\begin{array}{l}\text { Average } \\
\text { Module } \\
\text { Mark }\end{array}$ \\
\hline Module A & 57 & $70 \%$ & 42 \\
\hline Module B & 58 & $60 \%$ & 45.69 \\
\hline Module C eGirds & 58 & $88 \%$ & 55.79 \\
\hline Module D & 57 & $84 \%$ & 48.7 \\
\hline
\end{tabular}

It is also interesting to compare the results of the previous year with those above. (Only data for three modules is available at the time of writing.)

Table 5. Achievement Statistics for 2010 - 2011 Cohort

\begin{tabular}{|l|l|l|l|}
\hline & Enrolled & $\begin{array}{l}\text { Pass } \\
\text { Rate }\end{array}$ & $\begin{array}{l}\text { Average } \\
\text { Module } \\
\text { Mark }\end{array}$ \\
\hline Module A & 76 & 84 & 51.17 \\
\hline Module B & 62 & 82 & 55.5 \\
\hline Module C & 99 & 84 & 54.1 \\
\hline
\end{tabular}

In this data the modules have a similar pass rate and average module mark. The last entry in the table (Module C) is the previous year's version of the module (now modified to use the eGrids). This data appears to suggest that the eGrid model may facilitate improved student performance.

The improvement in module grades for the eGrids module may also be seen in the graph below. 


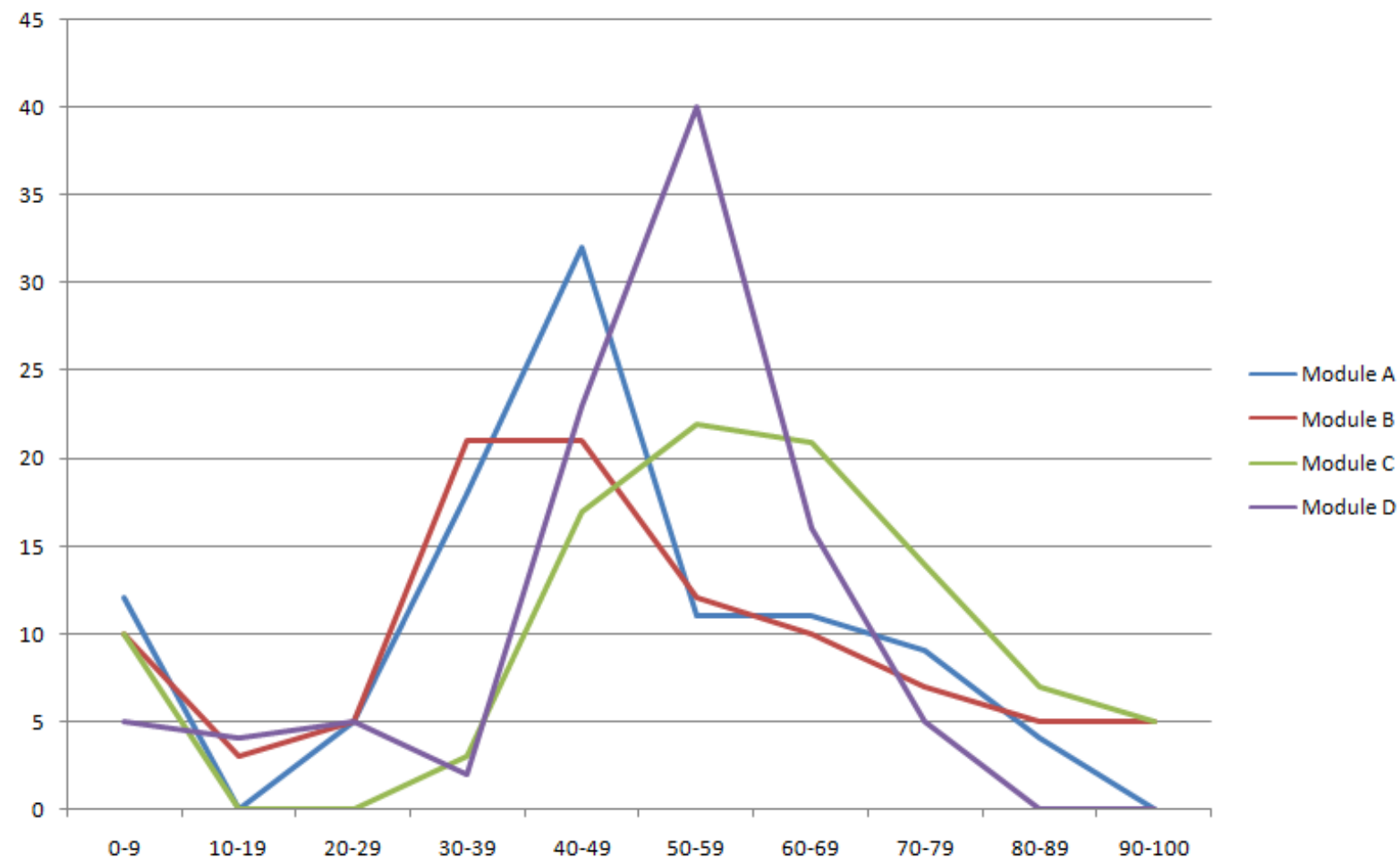

Figure 4. Grade Bands for 2011 - 2012 Cohort

This chart indicates the range of grades for each module during 2011 - 2012. Similar results were seen for the second program when comparing year on year module statistics. A better picture of the impact on progression and grades will become clearer as additional year on year data becomes available.

\section{Conclusions}

The style of assessment appears to have been well received by both staff and students. Students indicate that this model has a positive impact on their learning and the staff indicated that the assessment becomes more contained within the taught sessions.

Initial findings indicate a positive impact on NSS results, student progression and achievement along with some interesting insights into usage patterns of the software.

The students' voice indicates that they wanted more of the same type of assessment, more one to one contact longer time spent in lab based study.

Tutors suggested that it may be wise to provide more explicit instruction (via on-line video) as to the mechanics of the process. By providing a printed log book there is now a document that becomes a central focus of the dialogue and a record of the assessment process. Strengthening the team based elements of the assessment process has both served to strengthen the underlying pedagogy and make better use of the time spent in dialogue. It is the conclusion of the author that this project is worthy of further research and development.

\section{Acknowledgements}

Many thanks to Mike Leigh and the Pedagogic Interest Group for his help and support in obtaining the funding for this work and completing the paper. Thanks also go to all of the staff and students involved in the two modules and their invaluable contribution to this work.

\section{References}

[1] Beaumont, C. O'Doherty, M. Shannon, L. Reconceptualising Assessment Feedback : a Key to Improving Student Learning? Studies in Higher Education Vol. 36 No 6, 2012. p671-687

[2] Boud, D., and N. Falchikov. Assessment for the longer term. In Rethinking assessment in higher education, ed. D. Boud and N. Falchikov, 3-13. London: Routledge, 2007.

[3] Boud, D. Feletti, G. The Challenge of Problem Based Learning, Kogan Page, 2003.

[4] Brown, S., and P. Knight. Assessing learners in higher education. London: Kogan Page, 1994.

[5] Carless, D. The "Mini-Viva" as a Tool to Enhance Assessment for Learning. Assessment 7 Evaluation in Higher Education, Vol. 27, No 4, 2002. 
[6] Carless, D. Differing perceptions in the feedback process. Studies in Higher Education Vol. 31, No. 2, April 2006, pp. 219-233

[7] Chickering, A \& Gamson, Z. Seven Principles for Good Practice in Undergraduate Education AAHE bulletin, 39, 1987, p3-7

[8] Conaghan, P. Lockey, A. Feedback to Feed-forward, A Positive Approach to Improving Candidate Success. Notfall Rettungsmed, 9th September 2009.

[9] Denscombe, M. The Good Research Guide. Second Edition Open University Press, 2003.

[10] Dean, M. CTEC2404 Internet Software Development. http://www.cse.dmu.ac.uk/

$\sim$ mjdean/notes/modules/programming/ctec2404/1112/De

Montfort University, 2012.

[11] Dean, M. CTE2608 Multimedia and Internet Technology. http://www.cse.dmu.ac.uk/

$\sim$ mjdean/notes/modules/multimedia/CTEC2608/1112/ De Montfort University, 2012.

[12] Gibbs, G. Why Assessment is Changing. Innovation Assessment in Higher Education Bryan C. \& Klegg K. Routledge, Abingdon, 2006.

[13] Gibbs, G. \& Simpson C. Conditions under which Assessment Supports Students' Learning. Learning and Teaching in Higher Education, Issue 1, 2004-05.

[14] Hounsell, D. Contrasting conceptions of essaywriting. The experience of Learning Edinburgh, Scottish Academic Press, 1997.

[15] McTighe, J. \& O’Connor, K., Seven practices for effective learning, Educational Leadership, Association for Supervision and Curriculum Development. 63, 2005, p1017.

[16] National Student Survey. The National Student Survey 2005: summary report. Higher Education Funding Council for England. http://www.hefce.ac.uk/pubs/ rdreports/2006/rd22_06/rd22_06.doc, 2005.

[17] National Student Survey. The National Student Survey 2006: summary report. Higher Education Funding Council for England. http://www.hefce.ac.uk/ pubs/rdreports/2007/rd14_07/rd14_07sum.doc, 2006

[18] National Student Survey. Teaching quality information data. Higher Education Funding Council for England.http://www.hefce.ac.uk/

learning/nss/data/2007, 2007.

[19] National Student Survey. 2008 teaching quality information data. Higher Education Funding Council for England. http://www.hefce.ac.uk/learning/nss/ data/2008, 2008.

[20] National Student Survey. 2009 teaching quality information data. Higher Education Funding Council for England. http://www.hefce.ac.uk/ learning/nss/data/2009, 2009.

[21] Nicol, D. \& Macfarlane-Dick, D., Formative assessment and self-regulated learning: A model and seven principles of good feedback practice. Studies in Higher Education, Routledge, 31, 2006, p199-218

[22] Savin-Baden, M. Howell Major, C. Foundations of Problem Based Learning. The Society for Research into Higher Education, 2004

[23] Stefani, L. Assessment in Partnership with Learners. Assessment and Evaluation in Higher Education, 1998.

[24] Wiggins, G. Educative Assessment. Designing Assessments To Inform and Improve Student Performance. Jossey-Bass Publishers, 1998.

[25] Michaelson, L. Sweet, M. The Essential Elements of Team Based Learning. New Directions for Teaching and Learning, 2008: 7-27. doi: 10.1002/tl.330, 2008.

[26] Dean, M. CTEC2404 Internet Software Development Log Book. http://www.cse.dmu.ac.uk/ $\sim$ mjdean/notes/modules/programming/ctec2404/1213/cont ent/assignments/ctec2404\%20Log\%20Book.doc 2012. 